\title{
Epidemiology of firearm injuries in a Scandinavian trauma center
}

\author{
Pernilla Brandt Bäckman ${ }^{1}$. Louis Riddez ${ }^{1}$ Lennart Adamsson ${ }^{1} \cdot$ Carl-Magnus Wahlgren $^{1,2,3}$ (-)
}

Received: 8 March 2018 / Accepted: 29 October 2018 / Published online: 3 November 2018

(c) The Author(s) 2018

\begin{abstract}
Background There is a concern that civilian gunshot injuries in Europe are increasing but there is a lack of contemporary studies. The purpose of this study was to investigate the current epidemiology and outcome of firearm injuries.

Methods Retrospective cohort study of all patients $(n=235)$ treated for firearm injuries admitted to a Scandinavian trauma center between 2005 and 2016. Local and national trauma registries were used for data collection.

Results Mean age was 31.3 years ( $\mathrm{SD} \pm 12.9$; range $16-88$ years); $93.6 \%$ males; mean ISS was $14.3(\mathrm{SD} \pm 15.9) ; 31.9 \%$ $(75 / 235)$ had ISS $>15$. There was a significant increase in penetrating trauma $(P<0.001)$ and firearm injuries $(P<0.001)$ over the years. The most common anatomical location of firearm injury was the lower extremity, $(n=138 / 235 ; 38 \%)$, followed by the abdomen $(n=69 ; 19 \%)$, upper extremity $(n=53 ; 15 \%)$, chest $(n=50 ; 14 \%)$, and head and neck $(n=50 ; 14 \%)$. Ninety patients (38.3\%) had more than one anatomic injury location. There were in total 360 firearm injuries and 168 major surgical procedures were performed. 53\% $(n=125)$ of patients underwent at least one surgical procedure. The most common procedures were fracture surgery $42 \%(n=70 / 168)$, followed by laparotomy $30 \% \%(n=51)$, chest tube $17 \%(n=29)$, and thoracotomy $11 \%(n=18)$. Forty-one patients $(17 \%)$ had at least one major vascular injury $(n=54)$. The most common vascular injury was lower extremity vessel injuries, $26 / 54$ (48\%), followed by vessels in chest and abdomen. There was a significant increase in vascular injuries during the study period $(P<0.006)$. The 30 -day mortality was $12.8 \%(n=30) ; 24$ patients died within $24 \mathrm{~h}$ mainly due to injuries to the chest and the head and neck region.

Conclusions Firearm injuries cause significant morbidity and mortality and are an important medical and public health problem. In a Scandinavian trauma center there has been an increase of firearm injuries in recent years. The lower extremities followed by the abdomen are the dominating injured regions and there has been an increase in associated vascular injuries.
\end{abstract}

Keywords Gunshot wounds · Epidemiology · Firearm injuries

\section{Introduction}

Injury is a major global public health concern and is the largest single factor of death and severe disability for people younger than 45 years $[1,2]$. There is great variation in the epidemiology of penetrating trauma throughout the world. Each year approximately 30,000 patients in USA are

Carl-Magnus Wahlgren

carl.wahlgren@sll.se

1 Section of Acute and Trauma Surgery, Karolinska University Hospital, Stockholm, Sweden

2 Department of Molecular Medicine and Surgery, Karolinska Institutet, Stockholm, Sweden

3 Department of Vascular Surgery/Traumacenter Karolinska Karolinska Institutet, Karolinska University Hospital, 17176 Stockholm, Sweden hospitalized for gunshot wounds (GSW) and 2500 die in hospital [3]. When comparing to other high-income countries, firearm homicides are 19 times higher in USA [4]. Although annual homicides have decreased in South Africa, the country still faces a high rate of firearm-related violence that creates a huge burden on the healthcare resources [5].

Illegal weapons and gun violence is a rising problem in European countries. There is a concern that injuries and deaths caused by firearms are increasing. However, only a few European epidemiology studies of civilian firearm injuries can be found in the current literature [6, 7]. In Scandinavian countries injuries are as well a great public health problem. In Sweden, every year almost 3000 people die in accidents where falls and traffic accidents are dominating [8]. Blunt trauma is clearly dominating but an increasing trend of penetrating violence has been noted $[9,10]$. This study was conducted to investigate the contemporary 
epidemiology and patient outcome of firearm-related injuries in a Scandinavian trauma center.

\section{Methods}

\section{Study population}

This study is a single center retrospective cohort study of all $(n=235)$ patients treated for firearm injuries admitted to the trauma center, Karolinska University Hospital, Stockholm, Sweden, between 2005 and 2016. All patients of all ages admitted with firearm injuries to the trauma center were included. The catchment area of Stockholm County and the nearby region is approximately 2.5 million people. The study was approved by the local ethics committee in Stockholm which also waived the need for informed consent (2017/1485-31). There are no conflicts of interest.

\section{Study aims}

The primary aim was to investigate trends of firearm injuries during the study period. Secondary aims were to assess anatomical distribution of firearm injuries, operative procedures, vascular injuries, and 30-day mortality.

\section{Data collection}

Data on demographics as well as anatomical localization of injury, surgery, and mortality were extracted from the local hospital registry (Karolinska Trauma registry), and the national trauma registry, SweTrau. Karolinska Trauma registry started in January 2005 as an internal quality registry to improve hospital trauma care, and the national trauma registry, SweTrau started in 2011 [10]. Data access was approved by the registries. Also medical records were reviewed for complete data.

\section{Definitions}

Data were selected by the International Classification of Diseases (ICD) codes for injury mechanisms: X93-Assault by handgun discharge; X94-Assault by rifle, shotgun and larger firearm discharge; and X95-Assault by other and unspecified firearm discharge. A major vascular injury was defined as an injury to a specific vessel given a diagnostic code (ICD). Injury severity score (ISS) was used to measure injury severity after trauma. Minor surgical procedures such as wound debridement, wound exploration, and wound closure were excluded.

\section{Statistical analysis}

Data were presented as mean \pm SD. Descriptive statistics were performed for patient characteristics and outcome. Univariate analyses of binary and nominal variables were performed using cross-tabulations; values reported for the Pearson Chi-square and Fisher's exact tests. The Poisson regression model was used to analyze trauma trends over the years. $P$ values less than 0.05 were considered significant. Analysis was performed with IBM SPSS Statistics V22.0.

\section{Results}

\section{Patient demographics}

The study included 235 patients treated for firearm injuries; mean age was 31.3 years $(\mathrm{SD} \pm 12.9$; range $16-88$ years); $93.6 \%$ males and $6.4 \%$ women; mean ISS was 14.3 $(\mathrm{SD} \pm 15.9) ; 31.9 \%(75 / 235)$ had $\mathrm{ISS}>15$. Mean ventilator days was 1.20 days $(\mathrm{SD} \pm 4.35 ; n=49)$. Mean intensive care unit and hospital stay was 1.97 days $(S D \pm 5.2$; range $0-33$ days; $n=101$; year 2005-2012) and 8.3 days (SD \pm 14.1 ; range $0-87$ days), respectively.

The total trauma volume during the study period was 18 007 trauma admissions (Fig. 1) which yields 1.3\% (235/18
Fig. 1 Total trauma volume including blunt, stabbing, and firearm injuries between 2005 and 2016

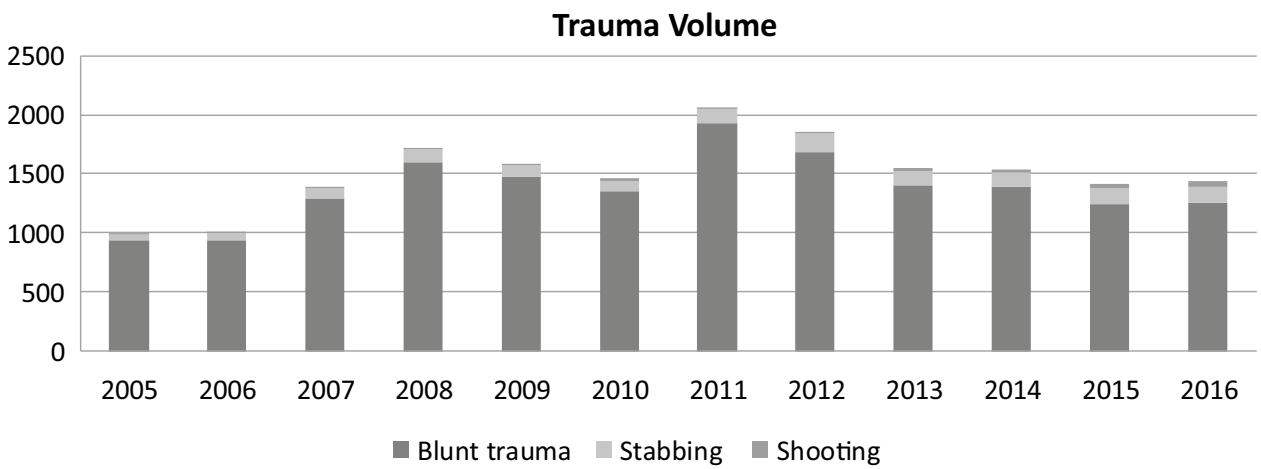


Fig. 2 Penetrating trauma admissions between 2005 and 2016
Fig. 3 Firearm injuries admissions between 2005 and 2016

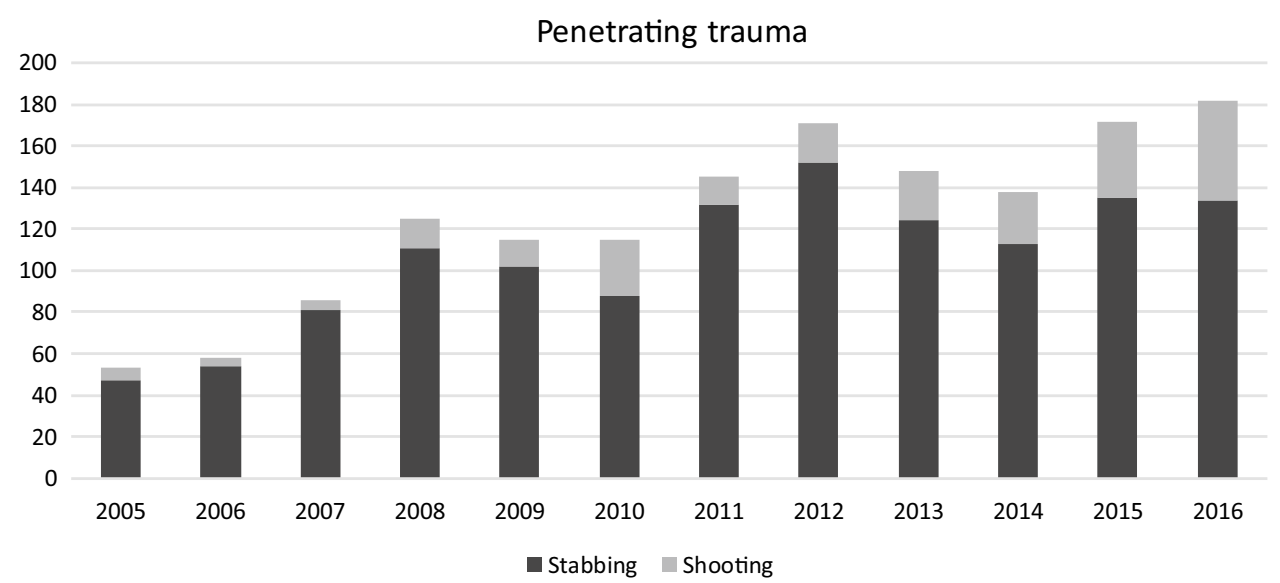

60

Firearm injuries

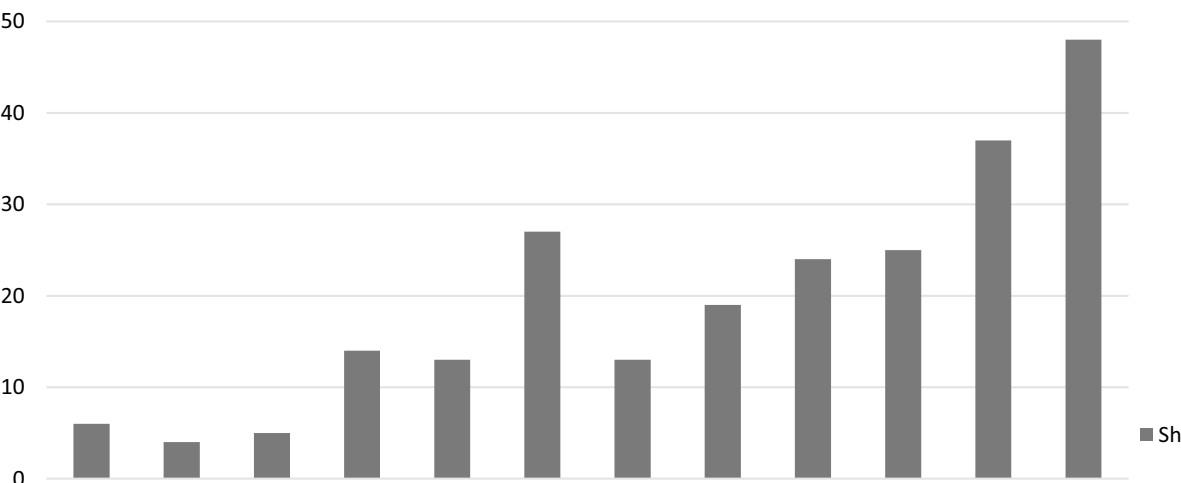

007) firearm injuries. The variation of trauma admissions during the time period was non-significant $(P=0.12)$. However, here was a significant increase in penetrating trauma $(P<0.001$; Fig. 2$)$ and firearm injuries $(P<0.001$; Fig. 3$)$ during the study period.

\section{Anatomic locations of firearm injuries}

The proportion of injuries in each anatomical zone is presented in Fig. 4. The most common anatomical location of firearm injury was the lower extremity, $(n=138 / 235$; $38 \%)$, followed by abdomen $(n=69 ; 19 \%)$, upper extremity $(n=53 ; 15 \%)$, chest $(n=50 ; 14 \%)$, and head and neck $(n=50 ; 14 \%)$. The total number of firearm injuries was 360 during the study period; injuries to the lower extremities clearly dominated over the years; Table 1.

Ninety patients $(38.3 \%)$ had more than one anatomic injury location; abdomen + lower extremity $(n=15)$ were dominating followed by chest + abdomen $(n=14)$ and upper + lower extremity $(n=9)$. Surgical procedures related to firearm injuries.

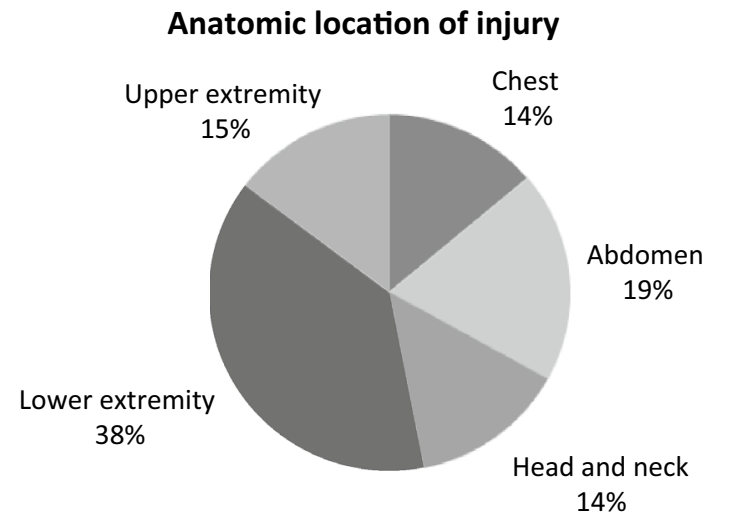

Fig. 4 Anatomic location of firearm injuries in 235 patients

$14 \%(29 / 206)$ and $6.1 \%$ (13/206) of patients required damage control laparotomy and thoracotomy, respectively, as the first key interventions for treatment and stabilization. There were four patients that underwent interventional radiology as the first key intervention. 45\% (93/206) did not require any emergency interventions performed for stabilization. There 
Table 1 The number of firearms injuries per year related to anatomic location is presented below

\begin{tabular}{lcrrrrr}
\hline Year & H\&N & UE & CHEST & ABDOMEN & LE & Total \\
\hline 2005 & 0 & 1 & 3 & 2 & 4 & 10 \\
2006 & 0 & 0 & 0 & 0 & 4 & 4 \\
2007 & 2 & 0 & 1 & 0 & 3 & 6 \\
2008 & 3 & 5 & 3 & 8 & 6 & 25 \\
2009 & 2 & 3 & 1 & 3 & 9 & 18 \\
2010 & 6 & 5 & 5 & 8 & 16 & 40 \\
2011 & 3 & 3 & 3 & 7 & 8 & 24 \\
2012 & 4 & 4 & 5 & 4 & 9 & 26 \\
2013 & 7 & 6 & 3 & 10 & 12 & 38 \\
2014 & 6 & 5 & 6 & 9 & 12 & 38 \\
2015 & 7 & 11 & 8 & 10 & 31 & 58 \\
2016 & 10 & 10 & 12 & 69 & 138 & 360 \\
Total & 50 & 53 & 50 & & & 73 \\
\hline
\end{tabular}

There were in total 360 firearm injuries in 235 patients

$H \& N$ head and neck, $L E$ lower extremity, $U E$ upper extremity
Table 2 Major surgical procedures $(n=168)$ after firearm injuries

\begin{tabular}{lllll}
\hline Year & $\begin{array}{l}\text { Fracture } \\
\text { surgery }\end{array}$ & Laparotomy & Chest tube & Thoracotomy \\
\hline 2005 & 2 & 2 & 3 & 1 \\
2006 & 1 & 0 & 0 & 0 \\
2007 & 0 & 0 & 0 & 1 \\
2008 & 3 & 7 & 3 & 1 \\
2009 & 6 & 3 & 0 & 1 \\
2010 & 12 & 5 & 3 & 2 \\
2011 & 6 & 4 & 1 & 1 \\
2012 & 6 & 5 & 4 & 0 \\
2013 & 7 & 3 & 4 & 2 \\
2014 & 5 & 7 & 3 & 2 \\
2015 & 10 & 7 & 2 & 3 \\
2016 & 12 & 8 & 6 & 4 \\
Total & 70 & 51 & 29 & 18 \\
\hline
\end{tabular}

was no extraperitoneal pelvic packing. Major surgical procedures $(n=168)$ that were performed after firearm injuries are presented in Table $2.53 \%$ of patients $(n=125 / 235)$ underwent at least one surgical procedure. The most common procedures were fracture surgery $42 \%(n=70 / 168)$, followed by laparotomy $30 \% \%$ ( $n=51 / 168)$, chest tube $17 \%$ $(n=29 / 168)$, and thoracotomy $11 \%(n=18 / 168)$. Fasciotomy was performed in $5.1 \%(n=12)$ of patients and other types of surgery in $4.7 \%(n=11)$.

Forty-six of the $69(67 \%)$ abdominal injuries underwent laparotomy. There were five patients who underwent laparotomy with no abdominal injuries that were injured in the chest. Patients with chest injuries $(n=50)$ were initially treated with chest tube $(n=27)$ and 15 patients underwent thoracotomy. One patient underwent thoracic spine

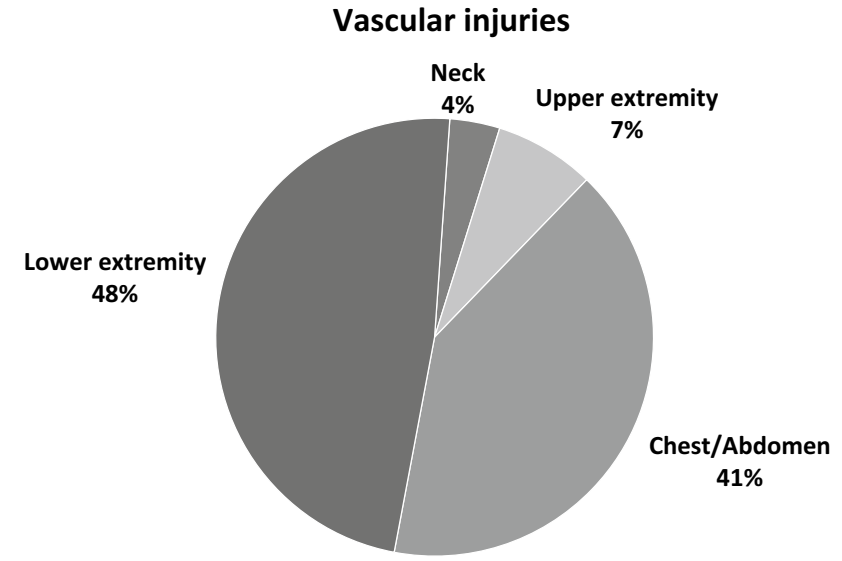

Fig. 5 The distribution of vascular injuries $(n=54)$ in anatomical zones after firearm injury

decompression, one patient had pharynx surgery, and 12 patients had no surgical intervention related to their chest injury.

\section{Vascular injuries}

Forty-one patients (17\%) had at least one major vascular injury; the total number was 54 . The most common vascular injury was lower extremity vessel injuries, $26 / 54$ (48\%), followed by vessels in chest and abdomen (Fig. 5). The femoral artery was the most common injured vessel; 13/54 (24\%) followed by injuries to inferior vena cava (9\%), visceral vessels (9\%) and iliac arteries (9\%) (Table 3). There was a significant increase in vascular injuries during the study period $(P<0.006)$. 
Table 3 Vascular injuries $(n=54)$ after firearms

\begin{tabular}{ll}
\hline Injured vessels & $N(\%)$ \\
\hline Carotid artery & $2(3.7)$ \\
Radial artery & $1(1.9)$ \\
Ulnar artery & $3(5.6)$ \\
Subclavian artery & $1(1.9)$ \\
Vertebral artery & $1(1.9)$ \\
Lung artery & $1(1.9)$ \\
Thoracic aorta & $2(3.7)$ \\
Abdominal aorta & $1(1.9)$ \\
Inferior vena cava & $5(9.3)$ \\
Mesenteric or coeliac artery & $5(9.3)$ \\
Renal artery & $1(1.9)$ \\
Iliac arteries & $5(9.3)$ \\
Other abdominal arteries & $2(3.7)$ \\
Femoral artery & $13(24)$ \\
Femoral vein & $5(9.3)$ \\
Popliteal artery & $2(3.7)$ \\
Popliteal vein & $1(1.9)$ \\
Anterior tibial artery & $1(1.9)$ \\
Other lower extremity arteries & $2(3.7)$ \\
Total & 54 \\
\hline
\end{tabular}

\section{Patient outcome}

The 30-day mortality after firearm injuries was $12.8 \%$ $(n=30) ; 24$ patients died within $24 \mathrm{~h}$. Among the 24 patients who died within $24 \mathrm{~h} ; 23$ patients were injured to the head and neck region or chest. Fourteen of the 24 patients had more than one injury location, ten had single injury location (head and neck area $n=6$; chest $n=4$ ). Twenty patients $(20 / 24 ; 83 \%)$ had a systolic blood pressure $<90 \mathrm{mmHg}$ when arriving to the emergency department.

The total number of deaths was $31(13.2 \%)$ during followup. The mean ISS for this group was $40.5(\mathrm{SD} \pm 22.4)$. The most common lethal injuries were distributed to the chest $(n=20)$ followed by the head and neck area $(n=18)$. Thirteen patients who died had major vascular injuries; the most common injured vessels were in the abdomen.

\section{Discussion}

This is the largest epidemiology study of firearm injuries in Sweden over a 12-year period at an urban major trauma center. There was a significant increase in number of firearm injuries over the years. During the study period, the percentage of penetrating trauma increased from 5.3\% 2005 to $12 \%$ 2016 , and the percentage of firearm injuries of all penetrating trauma increased from 16\% 2005 to $36 \% 2016$. Young age and men were dominating. The lower extremity was the most common injury location over the years and the femoral artery was the dominating vascular injury. $17 \%$ of patients had major vascular injuries which significantly increased over the years. More than one-tenth of patients died; the majority within $24 \mathrm{~h}$ mainly due to injuries to the head and neck area and the chest.

There have been relatively few studies published on epidemiology of civilian firearm injuries in European countries most likely explained by the low frequency of these injuries in most high-income countries. The Trauma Audit Research Network (TARN) database was used to examine adult persons hospitalized for penetrating trauma injury in England and Wales between 2000 and 2005, showing that stabbing was the most common type of injury (73\%) followed by shooting (19\%) [11]. Davies et al. showed that deaths and serious injuries from firearms remained rare in the civilian population of England and Wales although an upward trend has been described [7]. From an urbanized German region, a total of 121 patients sustained penetrating injuries by interpersonal violence or attempted suicide, 23 (19\%) of them by firearms [6]. The experience from Southwest Finland between 1997 and 2011 reported 130 penetrating trauma including 16 with a gun [12]. From the United States, using data from the National Inpatient Sample (NIS) during a 10-year period (2004-2013), the annual rate of hospitalizations for GSW was reported to remain stable at 80 per 100,000 hospital admissions [3]. From our data we clearly had an increasing trend of firearm injury admissions in recent years. The majority of patients were young males which has previously been reported [3, 6, 12-14].

Several factors such as wound ballistics, tissue structure, and anatomical relationships determine the extent of injury after firearms [15]. The most common anatomical location of injury was the lower extremities and the femoral artery was the most common injured vessel in this study. A review of the National Trauma Databank showed that the extremities are the most commonly injured anatomic region in nonfatal firearm trauma and are associated with high rates of vascular and bony injury [16]. Vascular injury, with or without fracture, was here the biggest predictor of local complications. The vascular trauma experience from a British trauma center showed that stab wounds were the most frequent cause of vascular injuries; five times more common than gunshot wounds [17]. Meskey et al. studied 650 patients with 938 fractures resulting from firearms where the femur $(30 \%)$ was the dominating fracture [18]. Ballistic fractures of the fibula and tibia were at increased risk for development of compartment syndrome.

We were somewhat surprised that only $53 \%$ of our study population underwent one or more surgical procedures. Livingstone et al. reported in a retrospective registry review of patients treated for GSW at an urban major trauma center in the US that $75 \%$ of patients admitted to hospital needed 
at least one surgical procedure during hospitalization [13]. Non-operative management and exclusion of minor surgery such as wound debridement, wound exploration, and wound closure may explain some of these differences. Almost threequarter of patients with GSW to the chest had surgical interventions including chest tube, thoracotomy or laparotomy.

The 30-day mortality after firearm injury was $12.8 \%$ in this study. The majority of these patients died within $24 \mathrm{~h}$ and some was more or less dead on arrival. The most common lethal injuries were distributed to the chest and the head and neck area. Gunshot wounds to the head carry a high mortality rate. Aarabi et al. showed that $76 \%$ of patients with civilian gunshot wounds to the head died at the scene of accident, and $61 \%$ of the patients who were admitted to hospital died [19]. Recent data from the American College of Surgeons (ACS) National Trauma Data Bank showed that firearm injuries have the highest case fatality rates in every age group with a mortality rate of $15.3 \%$ for GSWs [20].

There are some inherent limitations to this retrospective study based on registry data from two trauma registries Some of the study variables existed only in one registry. However, there are few missing data in the registries and patient charts could be used to control and complete data. Only patients admitted to the trauma center in the region were included in the study which may exclude patients with less severe injuries that may have been admitted to other hospitals. Also patients with firearm injuries that were already dead at the scene and did not reach the hospital were not included.

Firearm injuries cause significant morbidity and mortality and are an important medical and public health problem. In a Scandinavian trauma center there has been an increase of firearm injuries in recent years. The lower extremities followed by the abdomen are dominating injured regions and there has been an increase in associated vascular injuries. Most fatalities occur within $24 \mathrm{~h}$ due to injuries to the head and neck or chest. Additional studies and education on all levels of trauma care are necessary to further improve the management of patients with firearm injuries.

Acknowledgements We would like to thank Dr Olof Brattström, the national trauma registry SweTrau, for providing data, and Jonas Höijer, Unit of Biostatistics, Institute of Environmental Medicine, Karolinska Institutet, Stockholm, Sweden, for statistical consultations.

Funding No funding.

\section{Compliance with ethical standards}

Ethical statement The study was approved by ethics committee and performed in accordance with the ethical standards laid down in the Declaration of Helsinki and its later amendments.

Conflict of interest There are no conflicts of interest.
Ethical approval The study was approved by the local ethics committee in Stockholm which also waived the need for informed consent (2017/1485-31).

Informed consent The local ethics committee waived the need for informed consent.

Open Access This article is distributed under the terms of the Creative Commons Attribution 4.0 International License (http://creativeco mmons.org/licenses/by/4.0/), which permits unrestricted use, distribution, and reproduction in any medium, provided you give appropriate credit to the original author(s) and the source, provide a link to the Creative Commons license, and indicate if changes were made.

\section{References}

1. World Health Organization W. Injury and Violence: the facts 2014. Geneva: World Health Organization; 2014. http://www.who. int/violence_injury_prevention/media/news/2015/Injury_viole nce_facts_2014/en/. Accessed 2014.

2. Krug EG, Sharma GK, Lozano R. The global burden of injuries. Am J Public Health. 2000;90(4):523-6.

3. Cook A, Osler T, Hosmer D, Glance L, Rogers F, Gross B, GarciaFilion P, Malhotra A. Gunshot wounds resulting in hospitalization in the United States: 2004-2013. Injury. 2017;48(3):621-7.

4. Richardson EG, Hemenway D. Homicide, suicide, and unintentional firearm fatality: comparing the United States with other high-income countries, 2003. J Trauma. 2011;70(1):238-43.

5. Martin C, Thiart G, McCollum G, Roche S, Maqungo S. The burden of gunshot injuries on orthopaedic healthcare resources in South Africa. S Afr Med J. 2017;107(7):626-30.

6. Stormann P, Gartner K, Wyen H, Lustenberger T, Marzi I, Wutzler S. Epidemiology and outcome of penetrating injuries in a Western European urban region. Eur J Trauma Emerg Surg. 2016;42(6):663-9.

7. Davies MJ, Wells C, Squires PA, Hodgetts TJ, Lecky FE. Civilian firearm injury and death in England and Wales. Emerg Med J. 2012;29(1):10-4.

8. Swedish National Institute of Public Health. Personskador i Sverige. Stockholm: Swedish Civil Contingencies Agency (MSB); 2012. http://www.socialstyrelsen.se/publikationer2012/perso nskadorisverige. Accessed 2012.

9. SweTrau. Årsrapport SweTrau 2013. Stockholm: SweTrau; 2013. http://rcsyd.se/swetrau/wp-content/uploads/sites /10/2015/10/\%C3\%85rsrapport-SweTrau-2013_SKL.pdf. Accessed 2015.

10. Swetrau. Årsrapport SweTrau 2015.[internet]. Stockholm: Svenska Traumaregister; 2015. http://rcsyd.se/swetrau/wp-content/ uploads/sites/10/2016/11/\%C3\%85rsrapport-SweTrau-2015_ v1.2.pdf. Accessed 2015

11. Christensen MC, Nielsen TG, Ridley S, Lecky FE, Morris S. Outcomes and costs of penetrating trauma injury in England and Wales. Inj Int J Care Inj. 2008;39(9):1013-25.

12. Inkinen J, Kirjasuo K, Gunn J, Kuttila K. Penetrating trauma; experience from Southwest Finland between 1997 and 2011, a retrospective descriptive study. Eur J Trauma Emerg Surg. 2015;41(4):429-33.

13. Livingston DH, Lavery RF, Lopreiato MC, Lavery DF, Passannante MR. Unrelenting violence: an analysis of 6,322 gunshot wound patients at a Level I trauma center. J Trauma Acute Care Surg. 2014;76(1):2-9. 
14. Whittaker G, Norton J, Densley J, Bew D. Epidemiology of penetrating injuries in the United Kingdom: a systematic review. Int J Surg. 2017;41:65-9.

15. Stefanopoulos PK, Pinialidis DE, Hadjigeorgiou GF, Filippakis KN. Wound ballistics 101: the mechanisms of soft tissue wounding by bullets. Eur J Trauma Emerg Surg. 2017;43(5):579-86.

16. Berg RJ, Okoye O, Inaba K, Konstantinidis A, Branco B, Meisel E, Barmparas G, Demetriades D. Extremity firearm trauma: the impact of injury pattern on clinical outcomes. Am Surg. 2012;78(12):1383-7.

17. Perkins ZB, De'Ath HD, Aylwin C, Brohi K, Walsh M, Tai NR. Epidemiology and outcome of vascular trauma at a British Major Trauma Centre. Eur J Vasc Endovasc Surg. 2012;44(2):203-9.
18. Meskey T, Hardcastle J, O'Toole RV. Are certain fractures at increased risk for compartment syndrome after civilian ballistic injury? J Trauma. 2011;71(5):1385-9.

19. Aarabi B, Tofighi B, Kufera JA, Hadley J, Ahn ES, Cooper C, et al. Predictors of outcome in civilian gunshot wounds to the head. J Neurosurg. 2014;120(5):1138-46.

20. National Trauma Data Bank. National Trauma Data Bank, Annual Report 2016. Chicago: American College of surgeons; 2016. https ://www.facs.org/ /media/files/qualityprograms/trauma/ntdb/ntdba nnualreport2016.ashx. Accessed 2016 